\title{
Effect of Backpack Load Influencing the Cardio- Respiratory Changes in Stair Climbing in Adolescents
}

\author{
Mayura P. Deshmukh ${ }^{1}$, Tushar J. Palekar ${ }^{2}$, Mrudula V. Sangaonkar ${ }^{3}$, \\ Shilpa Khandare ${ }^{4}$
}

\author{
${ }^{1}$ Assistant Professor, Dr D Y Patil College of Physiotherapy, Pimpri, Pune \\ ${ }^{2}$ Principal and Professor, Dr D Y Patil College of Physiotherapy, Pimpri, Pune. \\ ${ }^{3}$ Assistant Professor, Dr D Y Patil College of Physiotherapy, Pimpri, Pune \\ ${ }^{4}$ Professor, Dr D Y Patil College of Physiotherapy, Pimpri, Pune
}

Corresponding Author: Mayura P. Deshmukh

\begin{abstract}
Postural and physiological changes are the distinct changes occurring in the adolescence which contributes fitness level of a child. The biomechanics of these children are highly affected by load carriage while climbing stairs which results in increase in cardio respiratory responses. Evaluation of the cardio respiratory changes is necessary in curbing further damage. In the study we evaluated the effect of backpack load influencing the cardio respiratory measures in stair climbing adolescents. 100 adolescents subjects aged 13-16 yrs were selected for the study, with graded loading for three consecutive days. Heart rate, rate of perceived exertion and respiratory rate were measured pre and post loading. Values of all the parameters on each day were compared. With increase in load, increase in heart rate, rate of perceived exertion and respiratory rate were significant when compared with progression in load. Although the measure which is highly affected amongst these was heart rate. The backpack with $30 \%$ load produces the elevation of variables at a greater extent hence there should be curbing of weight of $30 \%$ of adolescent's body weight.
\end{abstract}

Key Words: Adolescence, Backpack load, Rate of Perceived Exertion

\section{INTRODUCTION}

To carry books, sporting apparatus and other materials students of higher secondary carry backpack most often. Hikers, students and soldiers often use backpack as it is one of the several forms of manual and load carriage which provides versatility. ${ }^{[1]}$ To load the spine closely and symmetrically backpack is an appropriate way. ${ }^{[1]}$

Work load is relatively increased while climbing with a backpack; hence there is a change along the biomechanical requirement and need to perform on a higher rate. ${ }^{[4]}$ When walking with a backpack load, energy consumption is influenced by a proportional increase in metabolic costs to load. [5] Breathing conditions and other ventilator conditions are also altered. ${ }^{[4]}$

The anterior part of shoulder, situated in the region over brachial plexus, axillary artery and vein are often compressed by backpack straps. [2] Therefore, it may affect arm/hand circulation and sensation as it compresses the tissues. There is a relative decrease in walking speed, a decrease in walking time, an increase in cardio respiratory responses, and an increase in ground reaction forces is observed in several studies. ${ }^{[12]}$ 
As the heavy weight of the backpack rests on the frame which presses hard on the skin and muscle underneath, the type of distribution creates more problems with the external frame. ${ }^{[4]}$ It results in muscle soreness, blisters, fatigue and some critical musculoskeletal disorders, consequently making the adolescent students uncomfortable. ${ }^{[6]}$

Today, the concern regarding backpack use among children and adolescent students has been raised. Negative consequence of heavy loads on developing spine and the weight of children's school bag is an ongoing concern.

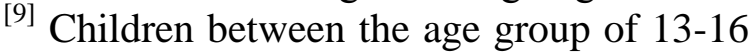
years are of great concern as junior students in secondary school have a critical spinal development stage. ${ }^{[3]}$

Osgood-Schlatter syndrome - one of the most common orthopedic diseases can be related by heavy loading on the patellar tendon leading to tendinopathy. Adding load can further worsen the condition for these school going children. Eccentric calf muscle strength should be of great concern for the same. ${ }^{[10]}$

Adolescent skeletal muscle and soft tissue and thus the spine structures are markedly different from adults as they experience a period of accelerated growth and development. However the children carrying backpack has affected posture, muscle activity, back pain and energy expenditure. ${ }^{[1]}$

The relationship between backpack carriage and cardio respiratory changes is touched by a very few investigators. Some studies suggest that heart rate increases when carrying backpack with different weights, without any significant changes in the load conditions. ${ }^{[2]}$ Some studies also suggests that walking with the backpack of greater than $10 \%$ of body weight induces significant changes in respiratory and cardiac parameters; however backpack of $10 \%$ of body mass shows no significant change in both cardio respiratory and postural parameter. ${ }^{[1][4]}$
Considering the backpack use in the school children of developing countries is $90 \%$, though load carriage is greater than recommended limit and also because of limited information about cardio respiratory effects of backpack, it is necessary to investigate the cardio respiratory changes particularly heart rate and rate of perceived exertion and to compare the changes induced by different weight of backpack load from rest to climbing stairs for 5 mins and 2 mins of recovery time. ${ }^{[1][4][6]}$

Adolescents have accelerated development, adolescents of age 13-16yrs; usually suffer from a wide range of postural, musculoskeletal and cardio respiratory changes. The children tend to fatigue very easily leading to increased rate of exertion. Work had been done related to backpack and rate of perceived exertion but there is a paucity of research in their perceived exertion and heart rate during stair climbing, thus there is need to work in this specific area. Also, there is a great possibility of interventional study on the same as there is likelihood of curbing further damage till adulthood.

Hence the aim of this study was to evaluate the effect of back pack load in school going adolescents specially while stair climbing taking the vitals like heart rate, respiratory rate and rate of perceived exertion.

\section{MATERIALS \& METHODOLOGY}

An Experimental Study was conducted in Krida Prabodhini School, Pimpri, Pune, Maharashtra, India, where the sample size was 100. All Children falling in of Age Group of 13-16 years and carrying school backpack to school were included in the study. Children with Musculoskeletal and cardiac disorder and Children above the age group of more than 13-16 yrs were excluded from the study. Rate of perceived exertion- Borg Scale, Heart rate - pulse oximeter, Timer were the outcome measure.

$$
\text { Material used were, Weighing }
$$

scales, Borg scale, Pulse oximeter, 
Backpack of school going children, Stationary, Timer.

The subjects were counselled about the test and how it is going to be performed. The advantages and disadvantages of the experiment were also explained. Demographic data of subjects were taken according to which children between 1316yrs of age were chosen for the experiment. Vitals were taken before the administration of the test i.e. heart rate, rate of perceived exertion and respiratory rate. Subjects were administered with $10 \%$ loads on the first day of the test. Subjects were supposed to climb stairs for three flights and come back to the point where they started the experiment. Subjects were asked to take rest and get ready for the experiment on the next day.

Subjects were administered with $20 \%$ loads on the second day of the test. Subjects were supposed to climb stairs for three flights and come back to the point where they started the experiment. Subjects were asked to take rest and get ready for the experiment on the next day.

Subjects were administered with $30 \%$ loads on the third day of the test. Subjects were supposed to climb stairs for three flights and come back to the point where they started the experiment.

The vitals were assessed post activity and were compared individually. The measures were also compared with each other to see which measure is highly affected.
Data Analysis and Interpretation: Data was recorded and documented in tables and graphs. Appropriate tests of statistics were applied based on Normality and data was checked for Normality. Data was not normally distributed for all the parameters so Non Parametric tests of significance were applied to check the level of significance.

In the present study Wilcoxon Signed Rank Test was applied as nonparametric a test of significance, and $\mathrm{P}$ Value for all the parameters was found to be $\mathrm{p}=0.000$ which denotes the highly significant.

\begin{tabular}{|c|c|c|c|c|c|}
\hline & & \multicolumn{3}{|c|}{$\begin{array}{l}\text { Wilcoxon Signed Rank } \\
\text { Test }\end{array}$} & \\
\hline $\begin{array}{l}\text { Sr } \\
\text { No }\end{array}$ & \multicolumn{2}{|c|}{ Parameters } & Zsub W & $\mathbf{P}$ & $\begin{array}{l}\text { Level of } \\
\text { Significance }\end{array}$ \\
\hline \multirow[t]{3}{*}{1} & \multirow[t]{3}{*}{ HR } & $10 \%$ & 8.682 & 0.000 & Highly Significant \\
\hline & & $20 \%$ & 8.682 & 0.000 & Highly Significant \\
\hline & & $30 \%$ & 8.639 & 0.000 & Highly Significant \\
\hline \multirow[t]{3}{*}{2} & \multirow{3}{*}{$\begin{array}{l}\text { RP } \\
\text { E }\end{array}$} & $10 \%$ & 8.853 & 0.000 & Highly Significant \\
\hline & & $20 \%$ & 8.8 & 0.000 & Highly Significant \\
\hline & & $30 \%$ & 8.612 & 0.000 & Highly Significant \\
\hline \multirow[t]{3}{*}{3} & \multirow[t]{3}{*}{ RR } & $10 \%$ & 8.701 & 0.000 & Highly Significant \\
\hline & & $20 \%$ & 8.695 & 0.000 & Highly Significant \\
\hline & & $30 \%$ & 8.689 & 0.000 & Highly Significant \\
\hline
\end{tabular}

\section{RESULT}

Table and Graph1 - Represents the mean difference of HEART RATE with different weight loads i.e. $10 \%, 20 \%$ and $30 \%$

HEART RATE

\begin{tabular}{|l|l|}
\hline Load carriage & Mean difference \\
\hline Ten percent & 22.61 \\
\hline Twenty percent & 33.32 \\
\hline Thirty percent & 45.4 \\
\hline
\end{tabular}

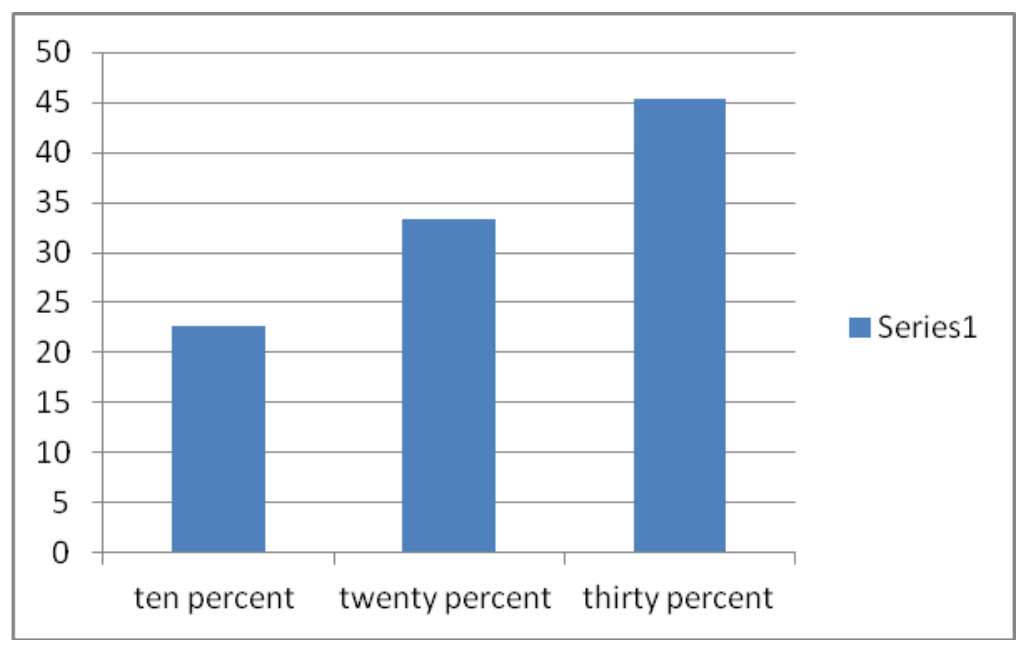


Interpretation: This graph illustrates the Mean difference of heart rate (post-pre) with different load carriage. The mean difference with $30 \%$ weight carriage shows the maximum increase in heart rate.

Table and Graph 2 - Represents the mean difference of RATE OF PERCEIVED
EXERTION with different weight loads i.e. $10 \%, 20 \%$ and $30 \%$

RATE OF PERCEIVED EXERTION

\begin{tabular}{|l|l|}
\hline Load carriage & Mean difference \\
\hline Ten percent & 1.96 \\
\hline Twenty percent & 2.5 \\
\hline Thirty percent & 3.82 \\
\hline
\end{tabular}

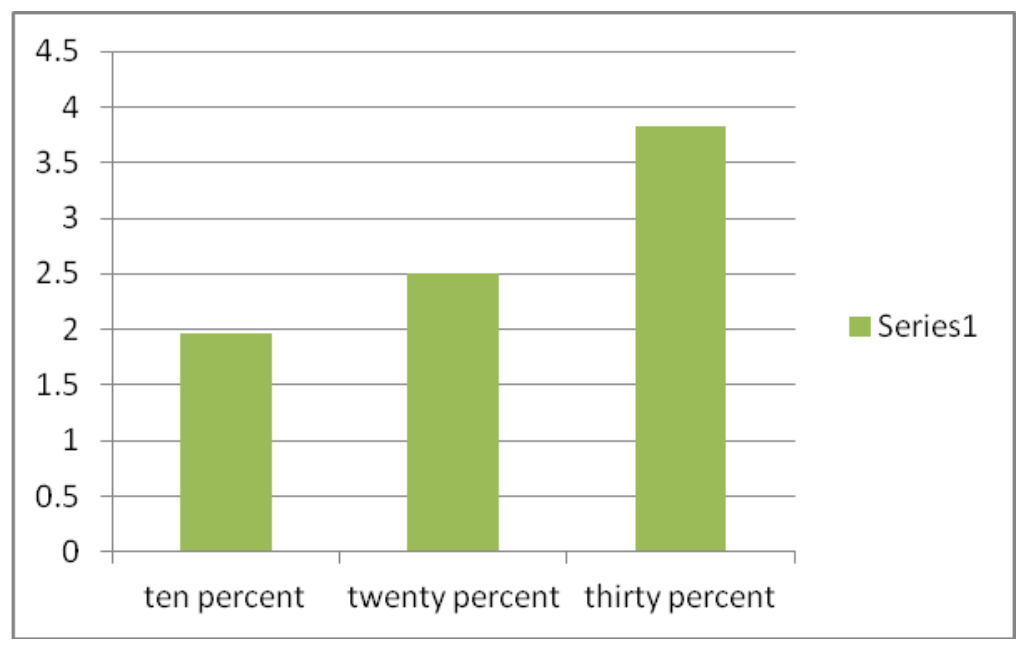

Interpretation: This graph illustrates the Mean difference of RATE OF PERCEIVED EXERTION (post-pre) with different load carriage. The mean difference with $30 \%$ weight carriage shows the maximum increase in heart rate

Table and Graph 3 - Represents the mean difference of RESPIRATORY RATE with different weight loads i.e. 10\%, $20 \%$ and $30 \%$.

\begin{tabular}{|l|l|}
\multicolumn{2}{l}{ RESPIRATORY RATE } \\
\begin{tabular}{|l|l|}
\hline Load carriage & Mean difference \\
\hline Ten percent & 6.3 \\
\hline Twenty percent & 8 \\
\hline Thirty percent & 11.1 \\
\hline
\end{tabular}
\end{tabular}

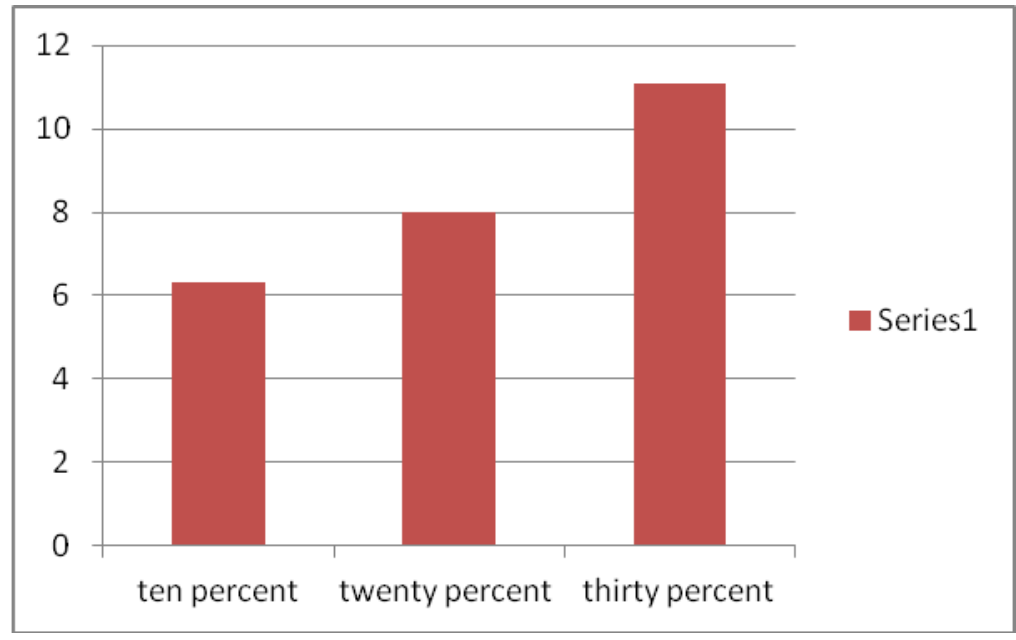

Interpretation: This graph illustrates the Mean difference of RESPIRATORY RATE (post-pre) with different load carriage. The mean difference with $30 \%$ weight carriage shows the maximum increase in heart rate
Table and Graph 4 - Represents the mean of pre and post HEART RATE assessment for $10 \%, 20 \%$ and $30 \%$ of backpack load. 
Mayura P. Deshmukh et.al. Effect of backpack load influencing the cardio-respiratory changes in stair climbing in adolescents.

HEART RATE

\begin{tabular}{|l|l|l|}
\hline Load Carriage & $\begin{array}{l}\text { Pre Assessment } \\
\text { Values }\end{array}$ & Post Assessment values \\
\hline Ten percent & 83.68 & 106.3 \\
\hline Twenty percent & 84.9 & 118.2 \\
\hline Thirty percent & 84.7 & 130.1 \\
\hline
\end{tabular}

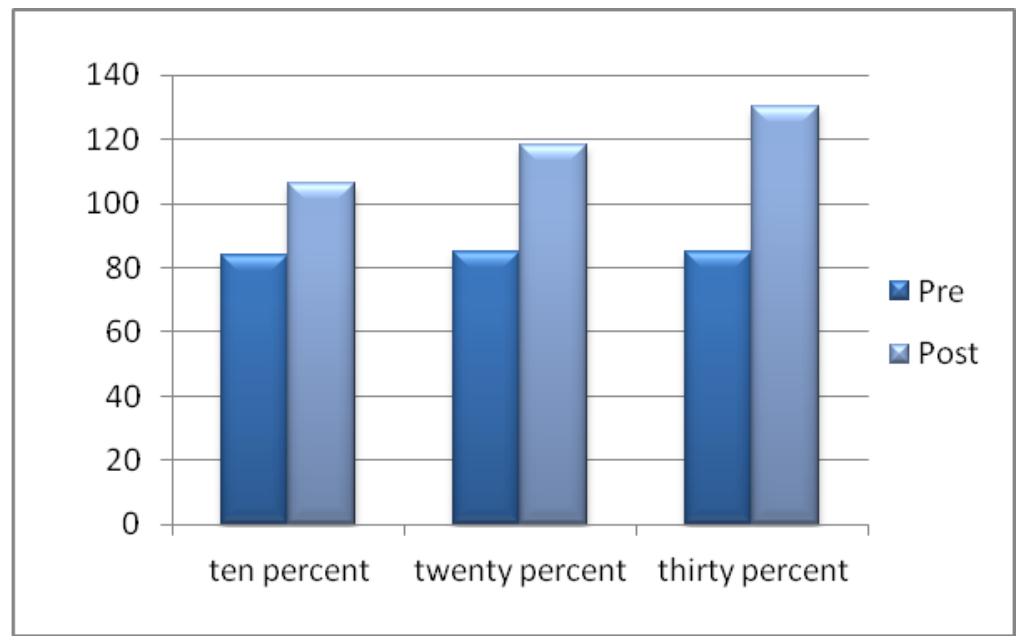

Interpretation: This graph illustrates the Mean of HEART RATE, pre assessment and post assessment with different load carriage. There is a successive increase in heart rate with rise in load carriage.

Table and Graph 5 - Represents the mean of pre and post RATE OF
PERCEIVED EXERTION assessment for $10 \%, 20 \%$ and $30 \%$ of backpack load.

\begin{tabular}{|l|l|l|} 
RATE OF PERCEIVED EXERTION \\
\begin{tabular}{|l|l|l|}
\hline $\begin{array}{l}\text { Load } \\
\text { Carriage }\end{array}$ & $\begin{array}{l}\text { Pre Assessment } \\
\text { Values }\end{array}$ & $\begin{array}{l}\text { Post Assessment } \\
\text { values }\end{array}$ \\
\hline Ten percent & 6.2 & 8.16 \\
\hline $\begin{array}{l}\text { Twenty } \\
\text { percent }\end{array}$ & 6.2 & 8.7 \\
\hline Thirty percent & 6.3 & 10.12 \\
\hline
\end{tabular}
\end{tabular}

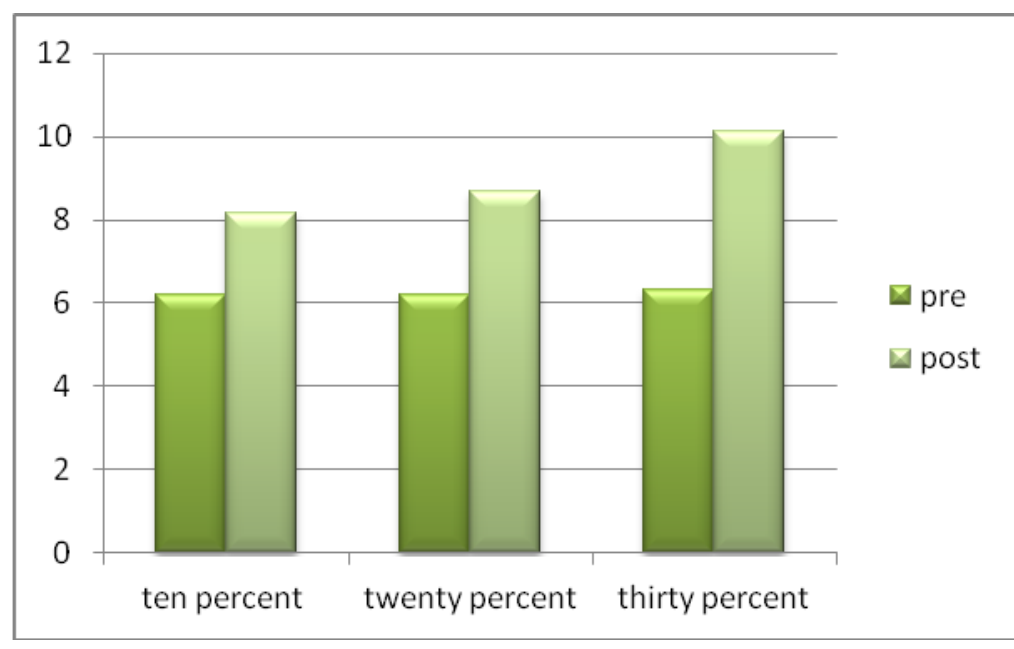

Interpretation: This graph illustrates the Mean of rate of perceived exertion, pre assessment and post assessment with different load carriage. There is a successive increase in heart rate with rise in load carriage.

Table and Graph 6- Represents the mean of pre and post respiratory rate assessment for $10 \%, 20 \%$ and $30 \%$ of backpack load.

RESPIRATORY RATE

\begin{tabular}{|l|l|l|}
\hline $\begin{array}{l}\text { Load } \\
\text { Carriage }\end{array}$ & $\begin{array}{l}\text { Pre Assessment } \\
\text { Values }\end{array}$ & $\begin{array}{l}\text { Post Assessment } \\
\text { values }\end{array}$ \\
\hline Ten percent & 12.6 & 18.9 \\
\hline $\begin{array}{l}\text { Twenty } \\
\text { percent }\end{array}$ & 13.5 & 21.5 \\
\hline Thirty percent & 13.7 & 24.8 \\
\hline
\end{tabular}




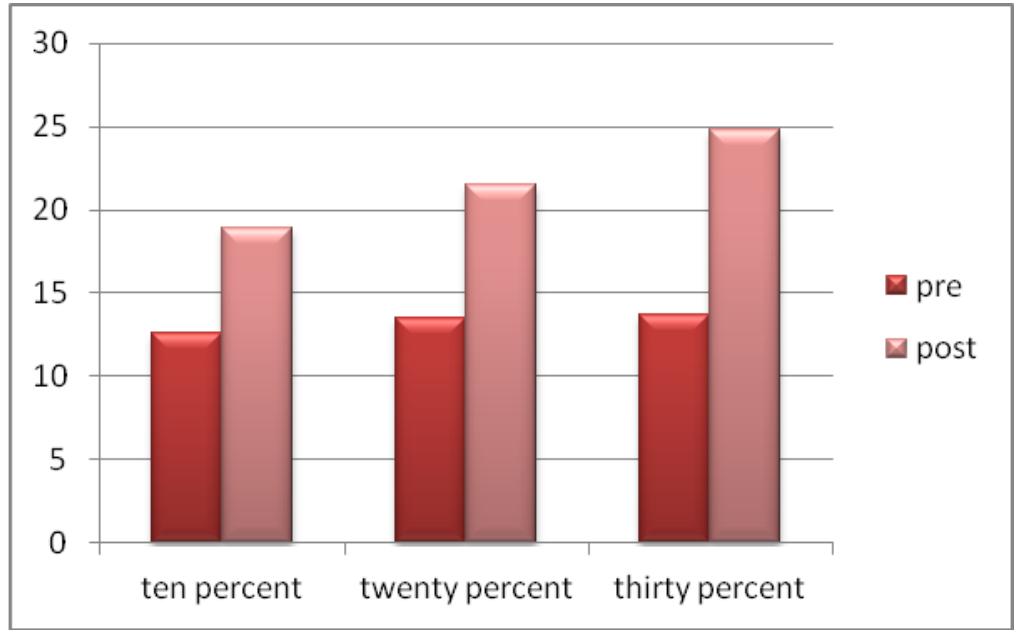

Interpretation: This graph illustrates the Mean of RESPIRATORY RATE, pre assessment and post assessment with different load carriage. There is a successive increase in heart rate with rise in load carriage.

Table and Graph 5 - Represents the mean difference of all measures to find the highest affected parameters among all. Assessment for $10 \%, 20 \%$ and $30 \%$ of backpack load.

HIGHEST PARAMETERS AMONG ALL

\begin{tabular}{|l|l|l|l|}
\hline & $\mathbf{1 0 \%}$ & $\mathbf{2 0 \%}$ & $\mathbf{3 0 \%}$ \\
\hline HR & 22.61 & 33.32 & 45.4 \\
\hline RR & 1.96 & 2.5 & 3.82 \\
\hline RPE & 6.3 & 8 & 11.1 \\
\hline
\end{tabular}

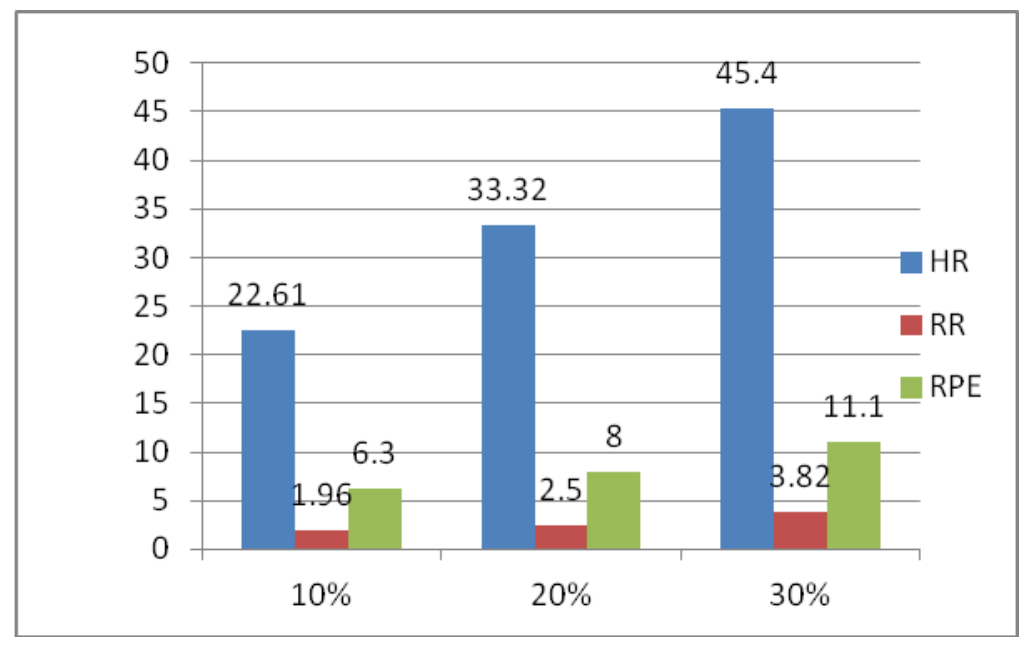

Interpretation: This graph illustrates the Mean difference for all 3 parameters and it shows the parameter which is highly affected? The table demonstrates that heart rate is affected the most while carrying backpack with different loads.

\section{DISCUSSION}

The study conducted aimed to analyze the effect of wearing backpack on cardio-respiratory changes while climbing stairs in young adolescents. In order to analyze the effect of difficulty with different weights i.e. $10 \%, 20 \%$ and $30 \%$ weight. The measures were found to increase with difficulty i.e. heart rate, rate of perceived exertion and respiratory rate. It became prominent with greater amount of backpack load while climbing stairs, more pronounced is the increase in the measuring parameters. However, the study conducted by Hong Y et Al. Concluded that there is a remarkable climb in heart rate with backpack load but minimal change with $10 \%$ of body weight carriage. $^{[21]}$ Changes in heart rate are directly proportional to the consequential 
increase in load. All students in this research have carried $10 \%, 20 \%$ and $30 \%$ body weight. The data obtained is more than that advocated by preceding researchers, who proposed that children should carry no more than $10 \%$ of their body weight. In a study conducted by $H$. Daneshmandi et. al. concluded that there is a possibility of interrelation of biomechanical changes with load carriage while exercising i.e. climbing stairs. ${ }^{[2]}$ Benedickt Gasser mentioned about the maximum weight carriage of $10 \%$, recommended for children and adolescent population as these are subjected to biomechanical changes in profusion. ${ }^{[1]}$ RPE was measured before and after stair climbing with backpack and a comparison was done between before and after stair climbing in individuals with different pack, the results of the study showed significant differences with $30 \%$ carriage of backpack. However, RPE was increased after carriage of all three backpacks. Siddharth Sen and Ajita believes, when students carrying load have significant climb in the exertion level and leads to fatigue of an individual which supports H. Daneshmandi et al quoting that loads of $0 \%$ is significantly different than loads of $10 \% \mathrm{BM}$ which leads to significant rise in physiological parameters. ${ }^{[3][16]}$ Moreover, the increase in RPE during stair climbing can also be explained by augmentation of perceived pulmonary effect that caused to pulmonary hyperventilation as mentioned by Siddharth et. al. RPE measures increased as the load was increased during stair climbing due to Metabolic acidosis which caused as a result of increased leg efforts from the beginning of stair climbing. ${ }^{[6]}$ Furthermore, RPE has been correlated with varied physiological indicators of exercise intensity such as oxygen consumption, blood lactate concentration, heart rate, blood pressure, serum levels and body temperature in varied terrains. ${ }^{[14]}$ There is minimum literature mentioning about the effect of backpack on respiratory rate though we can correlate RPE and respiratory rate physiologically. Lai and Jonas investigated the effect of backpack on lung volumes and respiratory rate. They reported that school bag heavier than $10 \%$ of the child's body weights has a repressing impact on respiratory rate and lung volumes. ${ }^{[20]}$ The study showed marked increase in respiratory rate as it is directly proportional to the level of fatigue experienced by the student while climbing stairs. Thus, it formulates a strong interrelation with increase in respiratory rate with gradual increase in load carriage. Carrying backpack has showed an effect on respiratory muscles, owing them to shorten with use of them in a long run. The intercostals muscles thus aren't able to expand fully during inspiration leading to increase in respiratory rate. ${ }^{[17]}$ It also signifies the increase in work of breathing after climbing stairs with heavy loads. ${ }^{[18][19]}$ The subjects taken in this study exercises regularly and have comparatively higher cardiovascular endurance than sedentary adolescents who doesn't exercise frequently. The subjects fall under normal BMI thus, we can assume the potential increase in measures with increase in BMI.

\section{CONCLUSION}

There is a conspicuous change in all three measures with progressive increase in load while climbing stairs. However, heart rate shows the maximum change amongst them. With greater load utmost changes were seen.

\section{Acknowledgement: None}

\section{Conflict of Interest: None}

\section{Source of Funding: None}

\section{Ethical Approval: Approved}

\section{REFERENCES}

1. Benedikt Gasser Backpack Load Influences Heart Rate While Climbing. July 2018, Vol 2 ; Issue 4:11

2. H. Daneshmandi et. Al. , Effect Of Carrying School Backpack On Cardio-Respiratory Changes in Adolescent Students. November 2008, Issue 4:7-14 
3. Siddhartha Sen And Ajitha, Influence Of Carrying Load On Rating Of Perceived Exertion And Heart Rate During Walking, 2016, Issue: 6:5

4. Yohei Kubori et Al. Association Between Pulmonary Function And Stair Climbing Test Results After Lung Resection : A Pilot Study, September 2018, Vol 2018, Article ID: 1925028.

5. Subhojit Chatterjee et. Al Effect of Heavy Load Carriage On Cardiorespiratory Responses With Varying Gradients And Modes of Carriage, 2018, Issue: 5:26

6. Pereira G, Correia R, Ugrinowitsch C, NakamuraF, Rodacki A, et Al.(2011), The rating of perceived exertion predicts intermittent vertical pump demand and performance. J Sport Sci 29:927-932

7. C A G Boreham et. Al Training Effects Of short Bouts Of Stair Climbing On C ardio Respiratory Fitness, Blood Lipids, homocysteine in Sedentary Young Women, $11^{\text {th }}$ January 2005 , issue: 39:590-593

8. Women's Heath and Children's Network, Puberty- Boy changes, Girl Changes, Kids health Topic (Government of South Australia)

9. Zeinab Javadiwala et. al. , Awareness Of Parents About Characteristic Of A Healthy Backpack , $4^{\text {th }}$ September 2018, Vol 2; Isuue : 2, 2018

10. M. Marzuki et. Al Effect Of Backpack's Weight on School Children- A Review, December 2009

11. Abeer Mohmoud Yousef, Effect Of Front PackAnd Backpack Load On Pulmonary Function Among 9-13yrs old Saudi Girls, Vol 6 ; Article 6.

12. Subhojit Chaterjee et Al. , Effect of Heavy load carriage on cardio respiratory response with varied gradients and modes of carriage,

13. Hseing Yu TSENG et. Al Effect of Load Carrying Methods And Stair Slopes on
Physiological Responses and Postures during Ascending And descending, March 23, 2010, Vol 49 ; issue- 30-36

14. Eston R, Lambrick D, Sheppard K, Parfitt G(2008) Prediction of Maximal oxygen uptake in sedentary males from a perpetually regulated, sub maximal graded exercise test J sport Sci 26:131-139

15. Pierrynowski MR, Winter DA, RW N (1981) Metabolic measures to ascertain the optimal load to be carried by man. Ergonomics 24:393-399

16. Devroey C, Jonkers I, de Becker et Al (2007) Evaluation of the effect of backpack load and position during standing and walking using biomechanical, physiological and subjective measures. Ergonomics 50:728-742.

17. Book for Human Physiology- Gyton

18. Fryer S, Giles D, Palomino IG, Puerta AO, Romero VE (2017) Haemodynamic and cardiorespiratory predictors of sport rock climbing performance. J Strength Cond Res 6:18

19. Giles LV, Rhodes EC, Taunton JE (2006) The physiology of rock climbing. Sports Med 36:529-545

20. Lai j, Jonas A(2001) The effect of shoulder girdle loading by a school bag on lung volumes in Chinese primary school children. Early Hum Dev62:79-86

21. Hong Y , Li JX , Wong ASK et Al. (2000) Effects of load carriage on heart rate, blood pressure and energy expenditure in children. Ergonomics 46:717-727

How to cite this article: Deshmukh MP, Palekar TJ, Sangaonkar MV et.al. Effect of backpack load influencing the cardio-respiratory changes in stair climbing in adolescents. Int $J$ Health Sci Res. 2021; 11(6): 329-336. DOI: https://doi. org/10.52403/ijhsr.20210649 